\title{
Assessment and Introduction of Quantitative Resistance to Fusarium Head Blight in Elite Spring Barley
}

\author{
A. Linkmeyer, M. Götz, L. Hu, S. Asam, M. Rychlik, H. Hausladen, M. Hess, and R. Hückelhoven
}

First, sixth, seventh, and eighth authors: Phytopathology, Technische Universität München, Freising, Germany; second author: Saatzucht Josef Breun GmbH \& Co. KG, Herzogenaurach, Germany; third, fourth, and fifth authors: Analytical Food Chemistry, Technische Universität München, Freising, Germany; and fifth author: BIOANALYTIK Weihenstephan, ZIEL Research Centre for Nutrition and Food Sciences Technische Universität München, Freising, Germany. Accepted for publication 7 June 2013.

\begin{abstract}
Linkmeyer, A., Götz, M., Hu, L., Asam, S., Rychlik, M., Hausladen, H., Hess, M., and Hückelhoven, R. 2013. Assessment and introduction of quantitative resistance to Fusarium head blight in elite spring barley. Phytopathology 103:1252-1259.

Breeding for resistance is a key task to control Fusarium head blight (FHB), a devastating disease of small cereals leading to economic losses and grain contamination with mycotoxins harmful for humans and animals. In the present work, FHB resistance of the six-rowed spring barley 'Chevron' to FHB in Germany was compared with those of adapted German spring barley cultivars. Both under natural infection conditions and after spray inoculation with conidia of Fusarium culmorum, F. sporotrichioides, and $F$. avenaceum under field conditions, Chevron showed a high level of quantitative resistance to the infection and contamination of grain with diverse mycotoxins. This indicates that Chevron is not only a

focal laser-scanning microscopy provided evidence that FHB resistance of Chevron is partially mediated by a preformed penetration resistance, because direct penetration of floral tissue by F. culmorum was observed rarely on Chevron but was common on susceptible genotypes. Alternatively, F. culmorum penetrated Chevron lemma tissue via stomata, which was unusual for susceptible genotypes. We generated double-haploid barley populations segregating for the major FHB resistance quantitative trait loci (QTL) Qrgz-2H-8 of Chevron. Subsequently, we characterized these populations by spray inoculation with conidia of $F$. culmorum and $F$. sporotrichioides. This suggested that Qrgz-2H-8 was functional in the genetic background of European elite barley cultivars. However, the degree of achieved resistance was very low when compared with quantitative resistance of the QTL donor Chevron, and the introgression of Qrgz-2H-8 was not sufficient to mediate the cellular resistance phenotype of Chevron in the European backgrounds.
\end{abstract} little susceptible to deoxynivalenol-producing Fusarium spp. but also to Fusarium spp. producing type A trichothecenes and enniatins. Monitoring the initial infection course of $F$. culmorum on barley lemma tissue by con-
Additional keywords: Hordeum vulgare.
Fusarium head blight (FHB) is a major disease of small cereals, including wheat (Triticum aestivum L.) and barley (Hordeum vulgare L.). The disease is caused by a complex of different Fusarium spp., including Fusarium avenaceum, F. culmorum, $F$. graminearum, F. poae, and F. sporotrichioides (32). However, of this complex $F$. graminearum (teleomorph Gibberella zeae) is the predominant causal agent of FHB worldwide. Fusarium spp. infect cereal spikes during flowering and colonize the developing kernels. Additionally, they produce mycotoxins, including the trichothecenes deoxynivalenol (DON), T-2 toxin (T-2), and HT-2 toxin (HT-2) and others such as enniatins (ENNs), beauvericin (BEA), and moniliformin, harmful to the health of humans and animals (7). Grain infection and mycotoxin contamination impair the quality of barley grain for use in malting, brewing, and animal feed $(17,31,40)$. Strategies to control FHB include changes in crop rotation and the use of fungicides (11). However, these measures alone are not sufficient to reduce the risk for FHB epidemics. Growing resistant cultivars as part of an integrated pest management system would be the most economic, ecologi-

Corresponding author: R. Hückelhoven;

E-mail address: hueckelhoven@wzw.tum.de

* The $e$-Xtra logo stands for "electronic extra" and indicates that Figure 1 appears in color online.

http://dx.doi.org/10.1094/PHYTO-02-13-0056-R

This article is in the public domain and not copyrightable. It may be freely reprinted with customary crediting of the source. The American Phytopathological Society, 2013. cal, and reliable approach to control FHB (25). However, little effort was put into FHB resistance breeding in European barley cultivars to date. Only limited sources of resistance to FHB in barley are available which derive from exotic and nonadapted cultivars, including 'AC Sterling', 'Chevron', 'Cl4196', 'Gobernadora', 'Harbin', 'Morrison', 'Seijo II', 'Symko', 'Zhedar I', and 'Zhedar' II (22). Biparental mapping studies involving these sources of FHB resistance identified numerous quantitative trait loci (QTL) for FHB severity and DON accumulation $(6,12-$ $14,24,26,39,45)$. Co-segregation of FHB QTL with morphological and physiological traits such as plant height, heading date, and row type or pleiotropic effects impede the identification of true FHB QTL $(6,14,26,45)$. The six-rowed spring barley Chevron, originating from Switzerland, was widely used as a genetic base for FHB resistance in American breeding programs. Two major QTL contributing to FHB resistance in Chevron are located on chromosome $2 \mathrm{H}$ and one minor QTL for reduced DON accumulation is located on chromosome $3 \mathrm{H}$. The resistant allele at the QTL $2 \mathrm{H}$ Bin 8 is associated with heading date $(5,6)$. Finemapping studies using near-isogenic lines (NILs) revealed that the association of heading date and FHB resistance is due to tight linkage of two different loci rather than pleiotropy (27). In contrast, association of FHB resistance and row type at the QTL $2 \mathrm{H}$ Bin 10 (26) is suggested to be due to pleiotropic effects (39). Negative agronomic traits such as weak straw, low grain yield and quality, as well as susceptibility to foliar diseases impeded the use of FHB resistance sources of exotic cultivars and breeding lines in the past. However, detailed characterization and fine mapping of 
the QTL Qrgz-2H-8 by Nduulu et al. (27) might facilitate the use of this QTL by marker-assisted selection and marker-assisted backcrossing to specifically improve FHB resistance in elite breeding lines or cultivars.

In this study, we report on the potential of using the moderately resistant Chevron to introduce FHB resistance in European elite barley cultivars. Resistance of Chevron to grain infection and mycotoxin contamination caused by relevant species of the FHB complex was analyzed by comparative artificial inoculation experiments under field conditions. Additionally, microscopic studies were conducted to provide insights into the cellular mechanisms underlying the resistance in Chevron. Finally, four double-haploid (DH) populations segregating for the major FHB resistance QTL Qrgz-2H-8 of Chevron in the genetic background of elite spring barley cultivars were generated and characterized following inoculation with Fusarium.

\section{MATERIALS AND METHODS}

Plant material. Four DH populations segregating for the FHB resistance QTL Qrgz-2H-8 of Chevron were generated. A QTL donor line was developed by a three-way cross of (Chevron $\times$ Felicitas $) \times 7708 \mathrm{e} 32$. Resulting F1 progenies were advanced by single-seed descent to F4 which were genotyped by the simplesequence repeat markers Bmag0015 and GMS03 flanking the target QTL region (27). Lines homozygous for the Chevron allele at the target QTL region were advanced to F7 and tested for agronomic traits under field conditions to select an appropriate two-rowed parental line (designated as '9763b'). Segregating populations were than generated by crossing $9763 \mathrm{~b}$ with the elite two-rowed spring barley 'JB Flavour', 'Sunshine', 'Marthe', and 'Jennifer'. DH lines were generated by microspore culture and the resulting candidates were genotyped as described before. In total, $129 \mathrm{DH}$ lines homozygous for the target QTL region were obtained, of which $62 \mathrm{DH}$ lines exhibited the Chevron allele and 67 $\mathrm{DH}$ lines the allele of the respective current parent. The individual populations comprised 56, 58, 8, and 7 lines for crosses with Jennifer, Sunshine, JB Flavour, and Marthe, respectively.

Fungal material and inoculum preparation. Strains of $F$. culmorum (Fc002), F. sporotrichioides (Fs002), and F. avenaceum (Fa002) were isolated from naturally infected barley grain. Singlespore isolates of these strains were used for artificial inoculation experiments. The strains TMW 4.0575 (F. sporotrichioides) and TMW 4.1863 (F. avenaceum) were provided by L. Niessen (Chair of Technical Microbiology, Technische Universität München). Fungal strains were maintained on potato dextrose agar at $20^{\circ} \mathrm{C}$, $60 \%$ relative humidity $(\mathrm{RH})$, and a cycle of UV light and darkness of 12 and $12 \mathrm{~h}$, respectively. For large-scale inoculum production, a mixture of oat and bruised wheat and barley kernels (1:1:1), soaked in $2 \%$ malt extract solution and autoclaved, was inoculated with individual Fusarium strains. The mixtures were incubated for 3 weeks as described above. Conidia were washed off the colonized seed with tab water containing $0.02 \%$ Tween 20 and the concentration was adjusted to $10^{5}$ conidia $/ \mathrm{ml}$.

Field experiments for evaluation of FHB resistance. The parental barley genotypes were evaluated in 2010 (Chevron and Sunshine) and 2011 (Chevron, Sunshine, JB Flavour, Jennifer, Marthe, and 9763b) for FHB resistance by artificial inoculation experiments in the field at Weihenstephan, $30 \mathrm{~km}$ north of $\mathrm{Mu}$ nich (Germany). The experimental layout was a randomized block design with four blocks exhibiting three $(2010, n=12)$ or four (2011, $n=16$ ) repeated plots of each genotype. Plots consisted of double rows, $80 \mathrm{~cm}$ in length, with $17-\mathrm{cm}$ row spacing and $30-\mathrm{cm}$ plot spacing. Sowing density was 40 seeds/plot. Soil and crop management as well as plant protection measures were carried out as required and customary in a place. Individual blocks were spray inoculated with conidia of F. culmorum, F. sporotrichioides, or $F$. avenaceum between mid-anthesis (growth stage [GS] 65) and early milk (GS 71) stage in a density of $7.5 \times 10^{7}$ conidia $/ \mathrm{m}^{2}$ using a backpack sprayer. The control block remained noninoculated. The treatment was repeated once 4 to 6 days after the first inoculation date to compensate for differences of cultivars in flowering date. Spray inoculation was carried out at sunset and inoculated plants were exposed to ambient conditions. Spikes of individual plots were harvested at barley dead ripening (GS 93). Seed were harvested with a single spike combine and cleaned with an ascending shifter. A sample of $100 \mathrm{~g}$ of each sample was milled to homogenous flour for DNA extraction and mycotoxin analysis (see below). Grain and flour were stored at $-20^{\circ} \mathrm{C}$ until further preparation.

Greenhouse experiment to characterize DH populations. The DH lines were analyzed for FHB resistance after spray inoculation with conidia of $F$. culmorum and $F$. sporotrichioides in a greenhouse experiment. Four barley plants per pot (in 3 liters of soil) grew under ambient conditions and were watered every 2 to 3 days. The experiment was set up in two completely randomized blocks with three repeated pots of each line. DH lines with aberrant time points of flowering were excluded from the experiment to avoid effects on infection rates due to developmental differences. At late anthesis (GS 69), plants were spray inoculated block-wise with conidia of either $F$. culmorum ( $\mathrm{Fc002}$ ) or $F$. sporotrichioides (Fs002) at a density of $7.5 \times 10^{7}$ conidia $/ \mathrm{m}^{2}$ by use of a backpack sprayer. Each block was covered separately with a tent of clear plastic foil and RH was kept at $100 \%$ by running atomizers for $48 \mathrm{~h}$. Visual assessments of FHB severity were carried out 14 days after inoculation (dai) for plants inoculated with F. culmorum and 21 dai for plants inoculated with F. sporotrichioides. The average percentage of necrotic kernels was estimated for each pot. Spikes of each pot were harvested separately at dead ripening (BBCH 93). Spikes were threshed, cleaned, milled, and stored as described before.

Isolation of genomic DNA from fungi. The strains TMW 4.0575, TMW 4.1863, and Fc002 were used to generate pure fungal DNA standards for quantitative polymerase chain reaction (qPCR). Fungal mycelia, grown for 7 days in $100 \mathrm{ml}$ of liquid malt broth (3\% malt extract and $0.3 \%$ peptone) at room temperature (RT) on a rotary shaker $(70 \mathrm{rpm})$, was filtered through folded filters (Schleicher \& Schuell, Germany), washed twice with $50 \mathrm{ml}$ of sterile tap water, and ground intensely using mortar and pestle in the presence of sterile sea sand. Isolation of genomic DNA from the ground mycelium was carried out according to Niessen and Vogel (30). Quantity and quality of DNA were measured by use of a microvolume spectrophotometer.

Isolation of genomic DNA from grain. Genomic DNA from grain was extracted according to the DNA extraction method recommended by the European Community Reference Laboratories for the isolation of maize DNA (19), with some modifications. Ground seed ( $2 \mathrm{~g})$ was mixed vigorously with $10 \mathrm{ml}$ of cetyltrimethylammoniumbromide (CTAB) extraction buffer $(2 \%$ CTAB, $1.4 \mathrm{M} \mathrm{NaCl}, 0.1 \mathrm{M}$ Tris base, $20 \mathrm{mM}$ EDTA, and $1 \%$ polyvinylpolypyrolidone-40, $\mathrm{pH} 8$ ). The mixture was incubated for $10 \mathrm{~min}$ at $65^{\circ} \mathrm{C}$. After centrifugation for $10 \mathrm{~min}(2,100 \times \mathrm{g}$, $\mathrm{RT}), 1 \mathrm{ml}$ of the supernatant was transferred to a new reaction tube. The solution was then mixed with 1 volume of chloroform/ isoamylalcohol (CIA, 24:1) and centrifuged (10 $\mathrm{min}, 16,200 \times g$, RT). Subsequently, a volume of $850 \mu \mathrm{l}$ of the supernatant was mixed with $8.5 \mu \mathrm{l}$ of a $10 \mathrm{mg} / \mathrm{ml}$ RNAse A solution and incubated for $30 \mathrm{~min}$ at $37^{\circ} \mathrm{C}$. Thereafter, $85 \mu \mathrm{l}$ of a CTAB solution $(10 \% \mathrm{CTAB}$ and $0.7 \mathrm{M} \mathrm{NaCl})$ was added followed by extraction with an equal volume of CIA (24:1). After centrifugation (10 min, $16,200 \times g, \mathrm{RT}), 700 \mu \mathrm{l}$ of the supernatant was mixed with a $1 / 10$ volume of the $10 \%$ CTAB solution, followed by extraction with an equal volume of CIA (24:1). After centrifugation (10 min, $16,200 \times g, \mathrm{RT}), 500 \mu \mathrm{l}$ of the upper aqueous phase was transferred to a new reaction tube and $1.5 \mathrm{ml}$ of precipitation buffer (1\% CTAB, 0.05 M Tris-base, and 0.01 M EDTA, pH 8) was 
added. The samples were mixed gently and kept at RT for $15 \mathrm{~min}$. The DNA was collected by centrifugation for $15 \min (16,200 \times g$, RT). The supernatant was discarded and the pellet was washed twice with $1 \mathrm{ml}$ of ethanol (70\%). The pellet was vacuum dried and resuspended in $120 \mu \mathrm{l}$ of double-distilled water. DNA quantity and quality was determined by using a microvolume spectrophotometer and the DNA concentration was adjusted to $20 \mathrm{ng} / \mu \mathrm{l}$ in double-distilled water.

Quantification of Fusarium DNA in barley grain. Grain infection rates with individual Fusarium spp. were determined by qPCR according to Nicolaisen et al. (28). DNA amplification was performed in a total volume of $20 \mu \mathrm{l}$ containing $10 \mu \mathrm{l}$ of $2 \times$ Maxima SYBR Green qPCR Master mix (Fermentas, St. LeonRot, Germany), forward and reverse primer at $300 \mathrm{nmol} / \mathrm{liter}$ each, $10 \mu \mathrm{g}$ of bovine serum albumin (BSA), and $100 \mathrm{ng}$ of genomic DNA. PCR amplification was carried out in duplicate in an MX3000P Cycler (Stratagene, Santa Clara, CA). The assay consisted of an initial step at $50^{\circ} \mathrm{C}$ for $2 \mathrm{~min}$ and $95^{\circ} \mathrm{C}$ for $10 \mathrm{~min}$, followed by 40 cycles of $95^{\circ} \mathrm{C}$ for $15 \mathrm{~s}$ and $60^{\circ} \mathrm{C}$ for $1 \mathrm{~min}$. The subsequent melting curve analysis was performed at 55 to $95^{\circ} \mathrm{C}$. In addition to primers specific for Fusarium spp., a barley DNA assay was included for normalization (28). Absolute quantification of barley and Fusarium DNA was carried out by external standard calibration. Therefore, dilution series $(100,10,1,0.1$, and $0.01 \mathrm{ng}$ of DNA) of pure fungal and barley DNA were generated and included in the qPCR analysis. Fungal DNA was diluted in Fusarium DNA-free barley DNA at $20 \mathrm{ng} / \mu \mathrm{l}$ to mimic matrix effects in DNA samples extracted from barley grain. Reproducibility, specificity, and sensitivity of the individual qPCR assays were reproduced according to Nicholaisen et al. (28).

Mycotoxin analysis. DON was analyzed by high-performance liquid chromatography coupled with UV light absorbance detection (HPLC-UV) after immunoaffinity cleanup according to a validated method (43). Analysis of T2, HT-2, ENN, and BEA was carried out by liquid chromatography tandem mass spectrometry (LC-MS/MS) based on a stable isotope dilution assay using $\left[{ }^{13} \mathrm{C}_{4}\right]-\mathrm{T} 2,\left[{ }^{13} \mathrm{C}_{2}\right]-\mathrm{HT} 2(1,38),{ }^{15} \mathrm{~N}_{3}$-labeled ENNs, and BEA (15) as the internal standards.

Confocal laser-scanning microscopy. For microscopic studies, two independent greenhouse experiments were conducted. Chevron and four DH lines of the cross Marthe $\times 9763 \mathrm{~b}$ segregating for the QTL Qrgz-2H-8 were grown in the greenhouse as described above with a 16-h light period at $15^{\circ} \mathrm{C}$ and $300 \mu \mathrm{mol} / \mathrm{m}^{2} / \mathrm{s}$ minimum light intensity and an 8 -h dark period at $12^{\circ} \mathrm{C}$. At anthesis, individual spikes were spray inoculated with $F$. culmorum conidia in distilled water with $0.02 \%$ Tween 20 at a density of $5 \times 10^{4}$ conidia/ml until run-off. Controls were sprayed with distilled Tween 20 -water. Inoculated spikes were covered with clear plastic bags for $48 \mathrm{~h}$ to facilitate high humidity. At 24, 48 , and $96 \mathrm{~h}$ after inoculation (hai), 20 lemmas of two individual spikes of each genotype and inoculation variant were harvested and transferred to $4 \mathrm{ml}$ of fixative solution (absolute EtOH/ chloroform [1:4], 0.15\% trichloracetic acid) each and incubated for at least $48 \mathrm{~h}$. Fixed lemmas were washed in distilled water and incubated for $20 \mathrm{~min}$ in phosphate buffered saline (PBS) (137 $\mathrm{mM} \mathrm{NaCl}, 2.7 \mathrm{mM} \mathrm{KCl}, 10 \mathrm{mM} \mathrm{Na} 2 \mathrm{HPO}_{4} \times 2 \mathrm{H}_{2} \mathrm{O}$, and $2 \mathrm{mM}$ $\mathrm{KH}_{2} \mathrm{PO}_{4}$ in distilled water, $\mathrm{pH}$ 7.4). Afterward, samples were transferred to the chitin-tagging WGA Alexa Fluor 488 staining solution $(4,900 \mu \mathrm{l}$ of PBS buffer and $50 \mu \mathrm{l}$ of WGA Alexa Fluor 488 at $1 \mu \mathrm{g} / \mu \mathrm{l})$ (Life Technologies, Darmstadt, Germany) and $50 \mu \mathrm{l}$ of BSA $(1 \mu \mathrm{g} / \mu \mathrm{l})$, vacuum infiltrated for $20 \mathrm{~min}$, and incubated for $48 \mathrm{~h}$ at $4^{\circ} \mathrm{C}$ in the dark. Samples were then transferred to a PBS buffer containing propidium iodide (SigmaAldrich, Steinheim, Germany) at $10 \mu \mathrm{g} / \mathrm{ml}$. After vacuum infiltration for $20 \mathrm{~min}$, samples were incubated for $48 \mathrm{~h}$ at $4^{\circ} \mathrm{C}$ in the dark. Fixed and stained samples were examined by confocal laser-scanning microscopy (CLSM) (Leica TCS SP5; Leica Microsystems, Wetzlar, Germany). Explants of 5 by $5 \mathrm{~mm}$ were pre- pared from the central region of the lemma tissue. Processes of infection, establishment, and colonization of barley epidermis and mesophyll cells were visualized by generating stacks of optical serial sections with an optical thickness of 1 to $2 \mu \mathrm{m}$. For excitation of WGA Alexa Fluor 488, a laser line of $488 \mathrm{~nm}$ was used. The resulting fluorescence emission was detected at 505 to $540 \mathrm{~nm}$. Propidium iodide was excited by a 561-nm laser line and fluorescence was detected at 590 to $650 \mathrm{~nm}$.

Statistics. Statistics were carried out with IBM SPSS statistics 19. Correlation analysis was done by the calculation of Spearman correlation coefficients. Comparison of means of multiple data sets was carried out by analysis of variance using the Tukey test based on a significance level of $P \leq 0.05$. Linear regressions were calculated to analyze association of the FHB resistance QTL Qrgz-2H-8 and different disease parameters.

\section{RESULTS}

Assessment of quantitative FHB resistance in the field. Grain infection with Fusarium spp. can be assessed by qPCR of fungal DNA $(28,29)$. We carried out field experiments to confirm and characterize the Chevron-mediated FHB resistance to German isolates of different Fusarium spp. First, we carried out pilot field experiments with and without artificial inoculation with $F$. culmorum, $F$. sporotrichioides, and $F$. avenaceum. This showed that content of Fusarium DNA as measured by qPCR in grain clearly reflected infection rates of respective Fusarium spp. as analyzed by mycological analysis (data not shown). DNA content and mycotoxin content were analyzed in Chevron, the breeding line 9763b exhibiting the Chevron allele at the FHB resistance locus Qrgz-2H-8, and four elite spring barley cultivars. Fungal DNA content of $F$. culmorum, $F$. sporotrichioides, and $F$. avenaceum and corresponding content of DON, T-2/HT-2, and ENNs in grain of the control plots, exposed to natural infection, are shown in Table 1. Low and consistent Fusarium DNA levels of 0.04 to $0.86 \mathrm{pg} / \mathrm{ng}$ of total DNA indicated low levels of natural infestation with $F$. culmorum and $F$. sporotrichioides. Hence, little differences between genotypes were observed, except for $F$. culmorum DNA content in 2010. Here, seed of Sunshine exhibited F. culmorum DNA at $3.07 \mathrm{pg} / \mathrm{ng}$ of total DNA. This level was $\approx 20$-fold higher compared with level in grain of Chevron ( $0.16 \mathrm{pg} / \mathrm{ng}$ of total DNA). Corresponding DON levels were 250 and $65 \mu \mathrm{g} / \mathrm{kg}$.

Chevron exhibited lowest DON content also in 2011 but differences between Chevron and the adapted cultivars were less strong when compared with 2010. Considerable levels of T-2 and HT-2 were observed in grain of Sunshine harvested in 2010 but not in grain of Chevron, although $F$. sporotrichioides DNA content was consistently low. In 2011, grain content of T-2 and HT-2 was 15 to $70 \mu \mathrm{g} / \mathrm{kg}$ and showed little differences between genotypes. Differences in FHB resistance between Chevron and the current cultivars were more pronounced for $F$. avenaceum DNA and ENN levels, probably due to a higher level of natural infection with this species when compared with F. culmorum and F. sporotrichioides. Fusarium DNA content in Chevron was 0.71 to $1.37 \mathrm{pg} / \mathrm{ng}$ of total DNA whereas DNA levels of JB Flavour, Jennifer, Marthe, and Sunshine and also of the QTL donor line 9763b were 3.52 to $17.49 \mathrm{pg} / \mathrm{ng}$ of total DNA. Correspondingly high levels of ENNs of 4,460 to $10,600 \mu \mathrm{g} / \mathrm{kg}$ were detected in grain of the latter genotypes whereas Chevron exhibited lower levels of 180 to $780 \mu \mathrm{g} / \mathrm{kg}$. The latter low ENN levels can be assumed to be significantly different from those of the other cultivars when considering the method's relative expanded measurement uncertainty of $25 \%$ (16).

Artificial inoculation with $F$. culmorum, F. sporotrichioides, and $F$. avenaceum resulted in a significant increase of fungal DNA content and toxin levels of grain of all genotypes and further confirmed the resistance of Chevron against these species 
(Table 2). F. culmorum DNA content was 149.77 to $209.48 \mathrm{pg} / \mathrm{ng}$ of total DNA in the adapted cultivars and 14.82 to $63.27 \mathrm{pg} / \mathrm{ng}$ of total DNA in grain of Chevron. DON content was 6,500 to 11,000 $\mu \mathrm{g} / \mathrm{kg}$ in grain of the adapted cultivars, whereas grain of Chevron contained DON at only 50 to $80 \mu \mathrm{g} / \mathrm{kg}$.

Chevron also revealed a high level of tolerance against infection and mycotoxin contamination after artificial inoculation with F. avenaceum. On average in both years, infection levels were $>5$-fold and ENN content $>12$-fold higher in grain of the adapted cultivars compared with Chevron (Table 2). Compared with $F$. culmorum and $F$. avenaceum, total infection rates and toxin levels were lower after inoculation with $F$. sporotrichioides. Nevertheless, Chevron was less susceptible to colonization and contamination of grain with T-2 and HT-2 compared with current barley cultivars (Table 2), the difference of which again can be assumed to be significant according to the relative expanded measurement uncertainty of $13 \%$ (16). The QTL donor line $9763 \mathrm{~b}$ showed intermediate infection rates between Chevron and the current cultivars JB Flavour, Marthe, and Sunshine after inoculation with $F$. sporotrichioides and $F$. avenaceum but was as susceptible as these cultivars after inoculation with F. culmorum. In contrast, the QTL donor line was as susceptible as the four current cultivars to mycotoxin contamination after inoculation with all three Fusarium spp. 9763b even showed the highest DON content, with $18,000 \mu \mathrm{g} / \mathrm{kg}$.

Microscopic evaluation of quantitative resistance. Comparative CLSM was carried out with lemma tissue of Chevron and DH lines segregating for the Chevron-derived QTL Qrgz-2H-8 spray inoculated with $F$. culmorum. Lemma tissue was sampled 24, 48, and 96 hai. To visualize fungal hyphae in the surrounding plant tissue, fungal structures were stained with WGA Alexa Fluor 488 and plant cell walls and nuclei by propidium iodide. In addition to cell walls and nuclei, propidium iodide also stained fungal hyphae. Therefore, fungal structures appeared red and green (Fig. $1)$. Regardless of the presence or absence of the Chevron-allele at the QTL Qrgz-2H-8, tissue colonization was similar in the four DH lines, indicating that the QTL alone did not have a major impact on the interaction. Until 48 hai, F. culmorum formed a hyphal network of long runner hyphae on the inner lemma surface. The fungus developed specific infection structures such as hyphal cushions originating from these runner hyphae (Fig. 1A). Starting from these structures, the fungus attacked the host tissue, and successful penetration of the cuticle became obvious by the formation of specific coralloid-like hyphal structures (Fig. 1B). Counterstaining of epiphytic hyphae with acidic ink indicated penetration sites beneath infection cushions and coralloid-like hyphae to be formed after primary penetration of the cuticle (not shown). Direct penetration of epidermal cells was frequently observed at trichomes (Fig. 1C). F. culmorum penetrated the base of the trichome and colonized the cell beneath the trichome. By contrast, lemma cuticle and epidermal cells of Chevron were penetrated less frequently when compared with the DH lines. $F$. culmorum formed superficial infection structures identical to those shown for the DH lines (Fig. 1A) but penetration appeared to be less successful. This conclusion is based on the observation of a high number of infection structures without successful penetration and less formation of specific coralloid-like hyphal structures. In general, lemma tissue was less colonized compared with the DH lines. Alternatively, lemma tissue of Chevron was often attacked and penetrated via stomata. Post-penetration fungal development remained usually restricted to the substomatal cavity at 48 hai (Fig. 1D and E). This observation differed from those of the DH lines, which showed few penetrated stomata and extensive mesophyll colonization.

Generation and characterization of QTL-carrying DH lines. We generated four $\mathrm{DH}$ populations segregating for the

TABLE 1. Fusarium DNA and mycotoxin contents in grain of spring barley genotypes exposed to natural infection (noninoculated control plots) ${ }^{\mathrm{z}}$

\begin{tabular}{|c|c|c|c|c|c|c|}
\hline \multirow[b]{2}{*}{ Year, genotype } & \multicolumn{2}{|c|}{ Fusarium culmorum } & \multicolumn{2}{|c|}{ F. sporotrichioides } & \multicolumn{2}{|c|}{ F. avenaceum } \\
\hline & DNA & DON & DNA & T-2/HT-2 & DNA & ENNs \\
\hline \multicolumn{7}{|l|}{2010} \\
\hline Chevron & $0.16 \mathrm{a}$ & 65 & $0.12 \mathrm{a}$ & 25 & $0.71 \mathrm{a}$ & 180 \\
\hline Sunshine & $3.07 \mathrm{~b}$ & 250 & $0.16 \mathrm{a}$ & 460 & $3.52 \mathrm{a}$ & 4,460 \\
\hline \multicolumn{7}{|l|}{2011} \\
\hline Chevron & $0.22 \mathrm{a}$ & 50 & $0.04 \mathrm{a}$ & 15 & $1.37 \mathrm{a}$ & 780 \\
\hline $9763 b$ & $0.46 \mathrm{a}$ & 100 & $0.41 \mathrm{a}$ & 20 & $4.87 \mathrm{a}$ & 6,760 \\
\hline JB Flavour & $0.86 \mathrm{a}$ & 120 & $0.10 \mathrm{a}$ & 70 & $14.73 \mathrm{~b}$ & 10,300 \\
\hline Jennifer & $0.27 \mathrm{a}$ & 90 & $0.60 \mathrm{a}$ & 25 & $17.49 \mathrm{~b}$ & 10,600 \\
\hline Marthe & $0.33 \mathrm{a}$ & 75 & $0.11 \mathrm{a}$ & 50 & $6.19 \mathrm{a}$ & 7,130 \\
\hline Sunshine & $0.58 \mathrm{a}$ & 140 & $0.08 \mathrm{a}$ & 25 & $5.28 \mathrm{a}$ & 9,800 \\
\hline
\end{tabular}

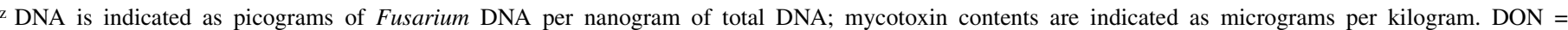
deoxynivalenol, T-2 = T-2 toxin, HT-2 = HT-2 toxin, and ENNs = enniatins; ENNs include group A, A1, B, and B1 ENNs. Statistically significant differences in DNA contents in columns are indicated by different letters according to Tukey test $(\alpha \leq 0.05)$.

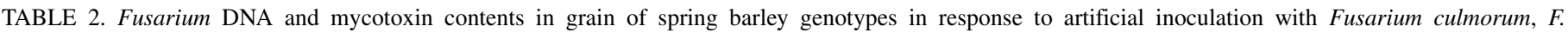
sporotrichioides, and F. avenaceum ${ }^{\mathrm{z}}$

\begin{tabular}{|c|c|c|c|c|c|c|}
\hline \multirow[b]{2}{*}{ Year, genotype } & \multicolumn{2}{|c|}{ F. culmorum } & \multicolumn{2}{|c|}{ F. sporotrichioides } & \multicolumn{2}{|c|}{ F. avenaceum } \\
\hline & DNA & DON & DNA & T-2/HT-2 & DNA & ENNs \\
\hline \multicolumn{7}{|l|}{2010} \\
\hline Chevron & $14.82 \mathrm{a}$ & 80 & $3.71 \mathrm{a}$ & 110 & $6.30 \mathrm{a}$ & 350 \\
\hline Sunshine & $160.63 \mathrm{~b}$ & 170 & $53.83 \mathrm{c}$ & 600 & $103.97 \mathrm{c}$ & 8,950 \\
\hline \multicolumn{7}{|l|}{2011} \\
\hline Chevron & $63.27 \mathrm{a}$ & 50 & $11.37 \mathrm{ab}$ & 110 & $26.26 \mathrm{a}$ & 2,730 \\
\hline $9763 b$ & $209.48 \mathrm{~b}$ & 18,000 & $27.96 \mathrm{abc}$ & 580 & $51.20 \mathrm{ab}$ & 22,900 \\
\hline JB Flavour & $175.14 \mathrm{~b}$ & 8,000 & $34.69 \mathrm{bc}$ & 450 & $110.96 \mathrm{c}$ & 24,000 \\
\hline Jennifer & $149.77 \mathrm{~b}$ & 6,500 & $28.86 \mathrm{abc}$ & 700 & $51.88 \mathrm{ab}$ & 22,900 \\
\hline Marthe & $202.99 \mathrm{~b}$ & 7,000 & $41.70 \mathrm{c}$ & 500 & $77.44 \mathrm{bc}$ & 7,880 \\
\hline Sunshine & $205.79 \mathrm{~b}$ & 11,000 & $50.52 \mathrm{c}$ & 1,900 & $88.09 \mathrm{bc}$ & 31,700 \\
\hline
\end{tabular}

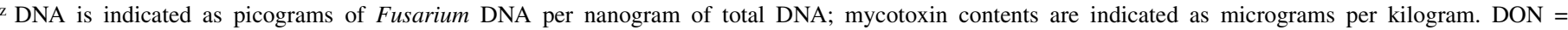
deoxynivalenol, T-2 = T-2 toxin, HT-2 = HT-2 toxin, and ENNs = enniatins; ENNs include group A, A1, B, and B1 ENNs. Statistically significant differences in DNA contents in columns are indicated by different letters according to Tukey test $(\alpha \leq 0.05)$. 
major FHB resistance QTL Qrgz-2H-8 of Chevron in the genetic background of German elite barley cultivars and analyzed them for FHB resistance. DH lines were spray inoculated with conidia of $F$. culmorum or $F$. sporotrichioides at early milk stage in the greenhouse. FHB severity and grain infection rates were determined by visual disease assessments and quantification of fungal DNA by qPCR. Additionally, grain content of mycotoxins was determined by LC-MS/MS. The presence of Qrgz-2H-8 was not generally detectable with respect to FHB severity and content of fungal DNA in the subpopulations of the four specific backgrounds Flavour, Jennifer, Marthe, and Sunshine (not shown). This was most likely due to the partially low number of individual lines generated in the populations and the high diversity of the genomic backgrounds in the DH lines. However, when we calculated the effect of Qrgz-2H-8 in $\approx 100 \mathrm{DH}$ lines tested independent of the background, a significant reduction was observed of Fusarium DNA content after introgression of the QTL. The effects of the target QTL on FHB severity and Fusarium DNA content across the four populations are shown in Table 3. Both traits revealed strong variation within individual allelic groups. A statistically significant association of the Chevron allele at the target QTL and FHB resistance was observed for Fusarium DNA content in grain after inoculation with $F$. culmorum and $F$. sporotrichioides. The QTL reduced grain DNA content by 16.5 or $17.6 \%$, respectively, and explained 4.3 or $5.6 \%$ of the phenotypic variation. Symptom formation was not significantly affected by Qrgz-2H-8. Targeted mycotoxin measurements in the DH population of Sunshine $\times 9763 \mathrm{~b}$ (18 lines with Sunshine allele versus 17 lines with Chevron allele at Qrgz-2H-8) revealed no significant effect of the QTL on toxin content after inoculation with either F. culmorum or F. sporotrichioides (data not shown).

\section{DISCUSSION}

Chevron is a six-rowed spring barley cultivar moderately resistant to FHB and DON contamination caused by F. graminearum $(4,37)$. Multiple QTL have been described and characterized for this cultivar with different impact on FHB severity and
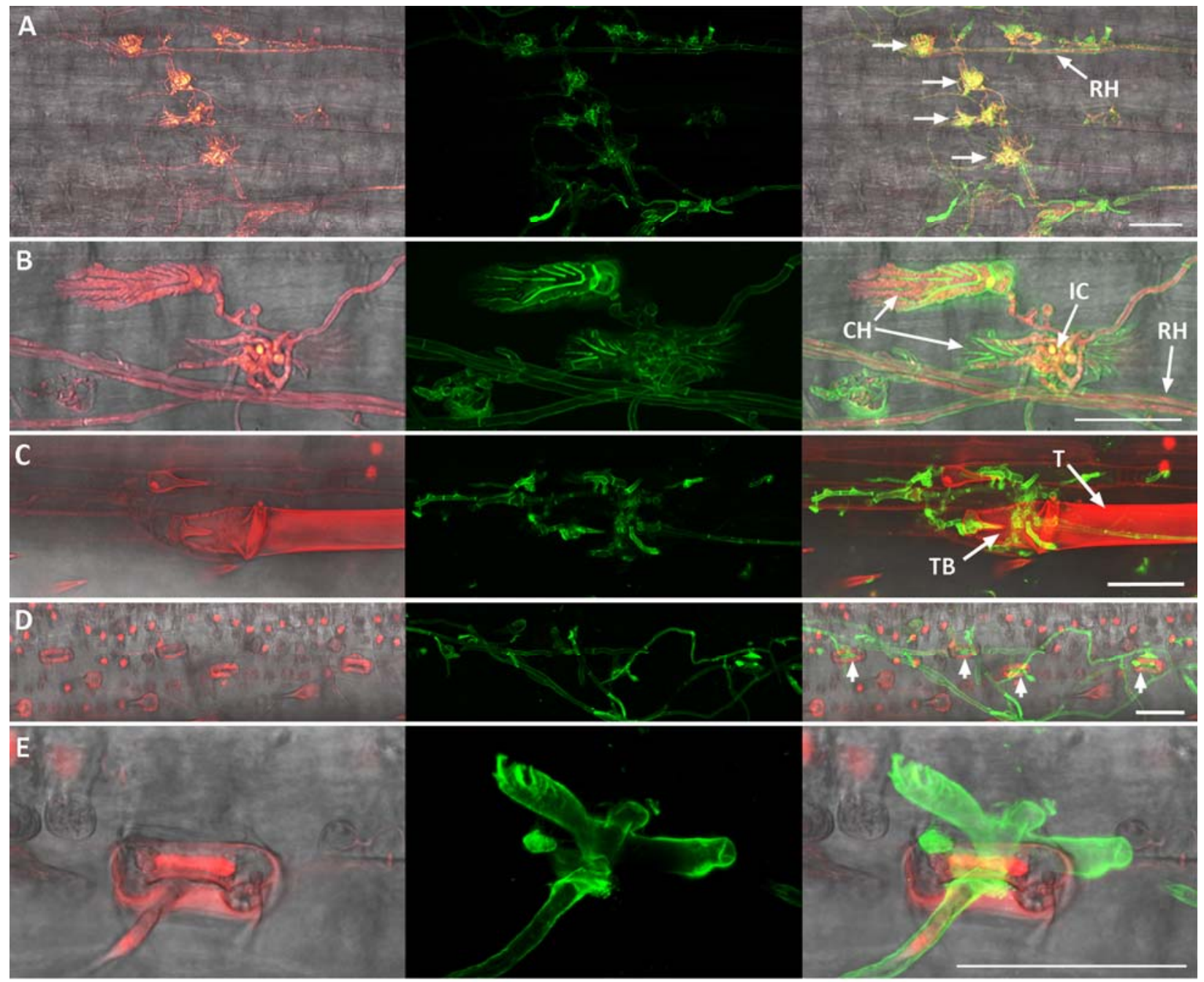

\section{transmission + propidium iodide}

\section{WGA-Alexa Fluor 488}

merged

Fig. 1. Comparative confocal laser-scanning microscopy of adaxial lemma tissue of Fusarium head blight-susceptible double-haploid (DH) lines from $\mathbf{A}$ to $\mathbf{C}$, the cross '9763b' $\times$ 'Marthe' and D and E, the moderately resistant 'Chevron' $48 \mathrm{~h}$ after spray inoculation with Fusarium culmorum. Host cell walls and fungal structures were stained by propidium iodide, and fungal structures were counterstained with green fluorescing WGA-Alexa Fluor 488. Figures are divided into the red fluorescing propidium iodide signals with transmission channel (left), the WGA-fluorescence image (middle), and the merge of both (right). A, Characteristic infection cushions (white arrows) generated by F. culmorum on the inner lemma surface and $\mathbf{B}$, formation of subcuticular coralloid-like hyphae after primary penetration of the cuticle. C, Penetration and colonization of a trichome. D and E, Stomata penetration of Chevron lemma tissue by F. culmorum. Abbreviations: $\mathrm{CH}=$ coralloid-like hyphae, $\mathrm{IC}=$ infection cushion, $\mathrm{RH}=$ runner hyphae, $\mathrm{T}=$ trichome, and $\mathrm{TB}=$ trichome base. Bars $=50 \mu \mathrm{m}$. 
DON contamination $(5,6,24)$. One of these loci, Qrgz-2H-8 on chromosome $2 \mathrm{H}$, has already been used for marker-assisted breeding for improved FHB resistance in American elite barley (27). In the present work, artificial inoculation experiments were conducted under field conditions to test FHB resistance of Chevron against German isolates of F. culmorum, F. sporotrichioides, and $F$. avenaceum. Compared with four two-rowed elite spring barley cultivars, Chevron showed high levels of quantitative resistance to grain infection and mycotoxin contamination even under conditions with high disease pressure. The strains used for artificial inoculation belong to the natural FHB complex of barley $(3,8,29,32)$ (our unpublished results) and represent groups of Fusarium spp. producing different classes of mycotoxins, including type A trichothecenes, type B trichothecenes, and ENNs (7). Previous studies showed that Chevron is highly resistant to the DON-producing species $F$. graminearum and $F$. culmorum $(4,22,35,42)$. Little is known about the underlying mechanism mediating FHB resistance of Chevron and whether the resistance is functional against other species such as $F$. avenaceum, F. sporotrichioides, F. poae, and F. langsethiae. Studies from different European countries demonstrated that these species can be of high relevance in spring barley apart from $F$. culmorum and $F$. graminearum $(16,29,41,44)$. For example, $F$. langsethiae has been shown to be responsible for considerable levels of T-2 and HT-2 in grain of spring barley in the United Kingdom, Norway, Finland, Denmark, France, and Germany $(10,21,29,44)$ (A. Linkmeyer, unpublished data). The present results provided evidence that Chevron comprises resistance to infection and mycotoxin contamination caused by a broad range of Fusarium spp. producing different classes of mycotoxins. With the development of a new protocol for measuring ENNs from infected grain (15), we were also able to show generally low ENN contamination of grain of Chevron. Therefore, FHB resistance of Chevron appears to be useful to control FHB in European spring barley which is caused by a diverse complex of Fusarium spp.

In noninoculated controls (Table 1), there was a positive association of $F$. culmorum DNA content and DON content and of $F$. avenaceum DNA and ENN content but not of $F$. sporotrichioides DNA and T2/HT2 content. The latter might be caused by low levels of natural infection with this fungus and by other Fusarium spp. contributing to T2/HT2 contamination in barley (29). Interestingly, after artificial inoculation in the field (Table 2 ), there was a trend for positive association of fungal DNA and respective toxin levels for all three Fusarium spp. Concurrently, the DNA and toxin levels were much higher than without inoculation. Thus, it might be important to artificially inoculate in future phenotyping for resistance against T2/HT2-generating fungi such as $F$. sporotrichioides.

Comparative microscopic studies provided insights into the mechanisms mediating FHB resistance in Chevron. On floral tissue of four DH lines of the cross $9763 \mathrm{~b} \times$ Marthe, F. culmorum showed a specific and complex strategy of penetration and coloni- zation. Specific infection structures such as infection cushions were formed from epiphytic runner hyphae, from which host tissue was penetrated. After initial penetration of the cuticle, the fungus formed characteristic coralloid-like hyphae in the subcuticular space. Similar infection structures and coralloid-like hyphae were observed by Pritsch et al. (34), Rittenour and Harris (36), and Boenisch and Schäfer (2) in the interaction of F. graminearum and wheat florets, indicating a conserved strategy among both Fusarium spp. Until 48 hai, the fungus colonized host tissue predominantly extracellularly. Direct penetration of epidermal cells occurred almost exclusively via trichomes at this time point. Peraldi et al. (33) also observed a large number of penetrated trichomes on floret tissue of Brachypodium distachyon, a grass model plant (9), following inoculation with $F$. graminearum. In addition to $F$. graminearum, targeted attack of trichomes also might appear as an important route of infection for F. culmorum. These observations of fungal penetration and colonization were similar in the four DH lines although two lines exhibited the Chevron allele at the FHB resistance locus Qrgz-2H-8 and two lines exhibited the Marthe allele at this locus. Hence, no effect of the QTL on FHB resistance could be attributed via microscopy. By contrast, we readily observed differences between Chevron and the four DH lines in pathogen interaction. Penetration of Chevron lemma cuticle and epidermal cells appeared later and was less successful compared with the DH lines. Generally, lemma tissue was colonized to a lesser extent at early times after inoculation (48 hai). These observations may indicate that FHB resistance in Chevron can be, at least in part, explained by a limited ability of the fungus to penetrate floral tissue. Instead, $F$. culmorum frequently penetrated stomata. Generally, penetration of stomata occurred rarely on the inner surface of lemma tissue of susceptible genotypes. Additionally, previous studies showed that penetration of host tissue via stomata is not a common or favored strategy of Fusarium spp. $(2,20)$. Stomata penetration has been shown to be more frequent on the abaxial surface of lemma tissue, where thick cell walls of epidermal cells prevent direct penetration $(23,36)$. These observations provided evidence that direct penetration of Chevron cuticle and epidermal cell walls is limited and stomata penetration might serve as an alternative method of infection. Jia et al. (18) found an induction of genes involved in cell wall functions in NILs with the Chevron allele at the major QTL Qrgz-2H-8, which might indicate a function of Qrgz$2 \mathrm{H}-8$ in penetration resistance via cell wall associated defense. However, according to our data, Qrgz-2H-8 alone was insufficient to mediate penetration resistance in the DH lines. In the present experiments, Chevron did not show activation of cell-wall-associated defense responses such as the formation of local cell wall appositions in response to fungal attack. However, it remains to be investigated in detail whether limited penetration of Chevron lemma tissue is linked with a constitutive defense response or with altered cell wall properties. One may further speculate that Chevron is less susceptible to Fusarium spp. because it does not support fungal development to a point when myco-

TABLE 3. Fusarium head blight (FHB) severity and fungal DNA content in grain of spring barley differing at Qrgz-2H-8 after artificial inoculation with either Fusarium culmorum or F. sporotrichioides in the greenhouse

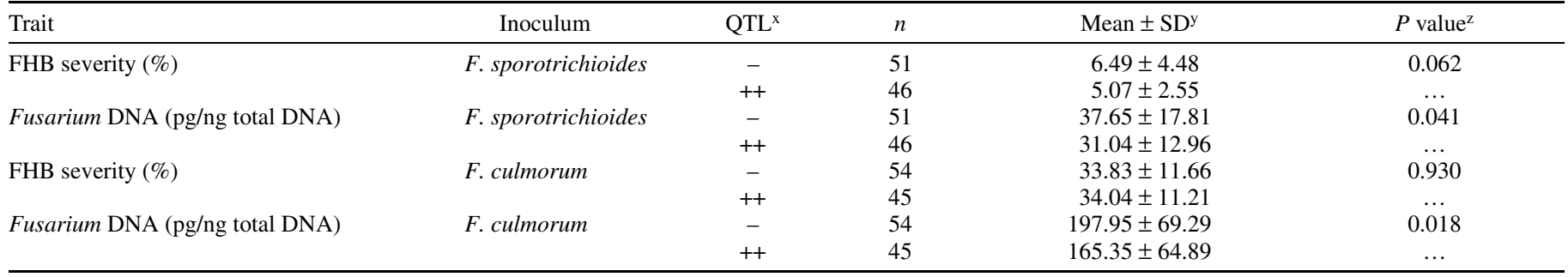

${ }^{\mathrm{x}} \mathrm{QTL}=$ quantitative trait loci. Homozygous presence or absence of Qrgz-2H-8 is indicated by ++ or - , respectively.

${ }^{\mathrm{y}} \mathrm{SD}=$ standard deviation.

z According to Tukey test. 
toxins are produced. This possibility arises from the fact that $F$. graminearum specifically activates DON-related gene expression in fungal infection structures during invasion of host tissue (2).

A set of DH lines segregating for the Chevron allele at the QTL Qrgz-2H-8 was generated and characterized for FHB resistance in an artificial inoculation experiment. A small effect of the QTL on FHB severity and grain infection was detectable after artificial inoculation with $F$. culmorum and $F$. sporotrichioides. However, the impact of the QTL was low and only significant when we increased the number of DH lines by analyzing the effect of the QTL independent of the genetic backgrounds of Flavour, Jennifer, Marthe, and Sunshine. Thus, Qrgz-2H-8 seems to be phenotypically detectable when introduced into European spring-barley but its contribution to FHB resistance is minor when applied alone and, hence, not satisfying concerning application. In the original study, which identified this QTL, the Chevron allele reduced FHB by $46 \%$ after inoculation with $F$. graminearum (6). Generally, effects of QTL on FHB are highly influenced by the environment, genetic background, infection pressure, and $\mathrm{Fu}$ sarium isolate used for artificial inoculation and, therefore, are difficult to compare. The DH lines in the present study showed strong variations in FHB resistance even within allelic groups. These strong variations might result from variable proportions of the Chevron genome in the DH lines on the one hand and of the genetic background of the adapted cultivars on the other hand. Thus, other genomic regions acting independently of the QTL Qrgz-2H-8 or genetically interfering with Qrgz-2H-8 might have influenced FHB severity in the DH lines and masked the effect of the target QTL. Therefore, it would be worthwhile to explore this phenoptypical variability by further genomic analysis. In the field experiments, the QTL donor line 9763b showed an intermediate level of grain infection rates between Chevron and the susceptible cultivars in the noninoculated controls and in response to inoculation with $F$. sporotrichioides and $F$. avenaceum. Upon inoculation with the highly aggressive $F$. culmorum, $9763 \mathrm{~b}$ was as susceptible as the current cultivars. Mycotoxin content in grain of $9763 \mathrm{~b}$ was generally at a similar level as in grain of the susceptible cultivars. Hence, in the genetic background of 9763b, the target QTL had low impact on grain infestation but no effect on mycotoxin contamination. NILs segregating for the QTL Qrgz$2 \mathrm{H}-8$ also indicated that the QTL reduces FHB severity but does not contribute to the reduction of DON content in grain (27). Additionally, the genetic background of the adapted cultivars may also possess genetic properties affecting FHB resistance. The four spring barley cultivars Flavour, Jennifer, Marthe, and Sunshine have not been analyzed for the presence of other QTL conferring FHB resistance but the artificial inoculation experiment under field conditions suggested possible variations in FHB susceptibility between these cultivars. Of the four German elite spring barley cultivars, Jennifer was least susceptible. FHB severity and grain infestation following inoculation with $F$. culmorum, $F$. sporotrichioides, and $F$. avenaceum ranked at a similar level as of the QTL donor line 9763b. These results indicate that Jennifer may exhibit genetic factors contributing to FHB resistance.

The present study indicated that the Chevron-derived FHB QTL Qrgz-2H-8 might be functional in the genetic background of European spring barley cultivars but only weakly contributes to FHB resistance. Thus, the QTL alone is not sufficient to mediate strong penetration resistance linked with low mycotoxin content as observed in Chevron.

\section{ACKNOWLEDGMENTS}

This research was funded by the Central Innovation Program SME of the German Federal Ministry of Economics and Technology. L. Hu thanks the China Scholarship Council and the Faculty Graduate Center Weihenstephan of TUM Graduate School at Technische Universität München for financial support. We thank L. Niessen (Chair of Technical Microbiology, Technische Universität München) for providing Fusarium strains; and A. Alkofer, T. Müller, A. John, and C. Zeck for their technical support.

\section{LITERATURE CITED}

1. Asam, S., and Rychlik, M. 2006. Synthesis of four carbon-13 labelled type A-trichothecene mycotoxins and their application as internal standards in stable isotope dilution assays, J. Agric. Food Chem. 54:65356546.

2. Boenisch, M. J., and Schäfer, W. 2011. Fusarium graminearum forms mycotoxin producing infection structures on wheat. BMC Plant Biol. $11: 110-124$

3. Bottalico, A., and Perrone, G. 2002. Toxigenic Fusarium species and mycotoxins associated with head blight in small-cereals in Europe. Eur. J. Plant Pathol. 108:611-624.

4. Buerstmayr, H., Legzdina, L., Steiner, B., and Lemmens, M. 2004. Variation for resistance to Fusarium head blight in spring barley. Euphytica 137:279-290.

5. Canci, P. C., Nduulu, L. M., Muehlbauer, G. J., Dill-Macky, R., Rasmusson, D. C., and Smith, K. P. 2004. Validation of quantitative trait loci for Fusarium head blight and kernel discoloration in barley. Mol. Breed. 14:91-104.

6. de la Pena, R. C., Smith, K. P., Capettini, F., Muehlbauer, G. J., GalloMeagher, M., Dill-Macky, R., Somers, D. A., and Rasmusson, D. C. 1999. Quantitative trait loci associated with resistance to Fusarium head blight and kernel discoloration in barley. Theor. Appl. Genet. 99:561-569.

7. Desjardins, A. E. 2006. Fusarium Mycotoxins: Chemistry, Genetics and Biology. American Phytopathological Society, St. Paul, MN.

8. Doohan, F. M., Brennan, J., and Cooke, B. M. 2003. Influence of climatic factors on Fusarium species pathogenic to cereals. Eur. J. Plant Pathol. 109:755-768.

9. Draper, J., Mur, L. A. J., Jenkins, G., Ghosh-Biswas, G. C., Bablak, P., Hasterok, R., and Routledge, P. M. 2001. Brachypodium distachyon. A new model system for functional genomics in grasses. Plant Physiol. 127:1539-1555.

10. Edwards, S. G. 2007. Investigation of Fusarium Mycotoxins in UK Barley and Oat Production. Home-Grown Cereals Authority, London.

11. Gilbert, J., and Tekauz, A. 2011. Strategies for management of Fusarium head blight (FHB) in cereals. Prairie Soils Crops 4:97-104. http:// www.prairiesoilsandcrops.ca

12. Hori, K., Kobayashi, T., Sato, K., and Takeda, K. E. 2005 QTL analysis of Fusarium head blight resistance using a high-density linkage map in barley. Theor. Appl. Genet. 111:1661-1672.

13. Hori, K., Sato, K., Kobayashi, T., and Takeda, K. 2006. QTL analysis of Fusarium head blight severity in recombinant inbred population derived from a cross between two-rowed barley varieties. Breed. Sci. 56:25-30.

14. Horsley, R. D., Schmierer, D., Maier, D., Kudrna, D., Urrea, C. A., Steffenson, B. J., Schwarz, P. B., Franckowiak, J. D., Green, M. J., Zhang, B., and Kleinhofs, A. 2006. Identification of QTLs associated with Fusarium head blight resistance in barley accession CIho 4196. Crop Sci. 46:145-156.

15. Hu, L., and Rychlik, M. 2012. Biosynthesis of ${ }^{15} \mathrm{~N}_{3}$-labeled enniatins and beauvericin and their application to stable isotope dilution assays. J. Agric. Food Chem. 60:7129-7136.

16. JCGM. 2008. Evaluation of Measurement Data-Guide to the Expression of Uncertainty in Measurement. Joint Committee for Guides in Metrology, Sevres Cedex, France.

17. Jestoi, M., Rokka, M., Yli-Mattila, T., Parrika, P., Rizzo, A., and Peltonen, K. 2004. Presence and concentrations of the Fusarium-related mycotoxins beauvericin, enniatins and moniliformin in Finnish grain samples. Food Addit. Contam. 21:794-802.

18. Jia, H., Millett, B.P., Cho, S., Bilgic, H., Xu, W. W., Smith, K. P., and Muehlbauer, G. J. 2011. Quantitative trait loci conferring resistance to Fusarium head blight in barley respond differentially to Fusarium graminearum infection. Funct. Integr. Genomics 11:95-102.

19. Joint Research Centre CRLfGFaF. 2007. Maize seed sampling and DNA extraction. Document CRLVL04/05XP. http//www.gmo-crl.jrc.ec.europa. eu/.../MIR604_DNAExtr.pdf

20. Kang, Z., and Buchenauer, H. 2000. Cytology and ultrastructure of the infection of wheat spikes by Fusarium culmorum. Mycol. Res. 104:10831093.

21. Langseth, W., and Rundberget, T. 1999. The occurrence of HT-2 toxin and other trichothecenes in Norwegian cereals. Mycopathologia 147:157-165.

22. Legge, W. G., Therrien, M. C., Tucker, J. R., Banik, M., Tekauz, A., Somers, D., Savard, M. E., Rossnagel, B. G., Lefol, E., Voth, D., Zatorski, T., Harvey, B. L., and Scoles, G. 2004. Progress in breeding for resistance to Fusarium head blight in barley. Can. J. Plant Pathol. 26:436-442.

23. Lewandowski, S. M., Bushnell, W. R., and Evans, C. K. 2006. Distri- 
bution of mycelial colonies and lesions in field-grown barley inoculated with Fusarium graminearum. Phytopathology 96:567-581.

24. Ma, Z., Steffenson, B. J., Prom, L. K., and Lapitan, N. L. V. 2000. Mapping of quantitative trait loci for Fusarium head blight resistance in barley. Phytopathology 90:1079-1088.

25. McMullen, M., Halley, S., Schatz, B., Meyer, S., Jordahl, J., and Ransom, J. 2008. Integrated strategies for Fusarium head blight management in the United States. Cereal Res. Commun. (Suppl. B.) 36:563-568

26. Mesfin, A., Smith, K. P., Dill-Macky, R., Evans, C. K., Waugh, R., Gustus, C. D., and Muehlbauer, G. J. 2003. Quantitative trait loci for Fusarium head blight resistance in barley detected in a two-rowed by sixrowed population. Crop Sci. 43:307-318.

27. Nduulu, L. M., Mesfin, A., Muehlbauer, G. J., and Smith, K. P. 2007. Analysis of the chromosome $2(2 \mathrm{H})$ region of barley associated with the correlated traits Fusarium head blight resistance and heading date. Theor. Appl. Genet. 115:561-570.

28. Nicolaisen, M., Suproniene, S., Nielsen, L. K., Lazzaro, I., Spliid, N. H., and Justesen, A. F. 2009. Real-time PCR for quantification of eleven individual Fusarium species in cereals. J. Microbiol. Methods 76:234240.

29. Nielsen, L. K., Jensen, J. D., Nielsen, G. C., Jensen, J. E., Spliid, N. H., Thomsen, I. K., Justesen, A. F., Collinge, D.B., and Jørgensen, L. N. 2011. Fusarium head blight of cereals in Denmark: Species complex and related mycotoxins. Phytopathology 101:960-969.

30. Niessen, L., and Vogel, R. F. 1997. Specific identification of Fusarium graminearum by PCR with gaoA targeted primers. Syst. Appl. Microbiol. 20:111-123.

31. Oliveira, P. M., Mauch, A., Jacob, F., Waters, D. M., and Arendt, E. K. 2012. Fundamental study on the influence of Fusarium infection on quality and ultrastructure of barley malt. Int. J. Food Microbiol. 156:3243.

32. Parry, D. W., Jenkinson, P., and McLeod, L. 1995. Fusarium ear blight (scab) in small grain cereals-a review. Plant Pathol. 44:207-238.

33. Peraldi, A., Beccari, G., Steed, A., and Nicholson, P. 2011. Brachypodium distachyon: A new pathosystem to study Fusarium head blight and other Fusarium diseases of wheat. BMC Plant Biol. 11:100-114.

34. Pritsch, C., Muehlbauer, G. J., Bushnell, W. R., Somers, D. A., and Vance, C. P. 2000. Fungal development and induction of defense response genes during early infection of wheat spikes by Fusarium graminearum. Mol.
Plant-Microbe Interact. 13:159-169.

35. Prom, L. K., Steffenson, B. J., Salas, B., Moss, J., Fetch, T. G., Jr., and Casper, H. H. 1996. Evaluation of selected barley accessions for resistance to Fusarium head blight and deoxynivalenol concentration. Pages 764-766 in: Proc. V Int. Oat Conf. VII Int. Barley Symp. G. J. Scoles and B. G. Rossnagel, eds. Univ. Ext. Press, University of Saskatchewan, Saskatoon, SK, Canada.

36. Rittenour, W. R., and Harris, S. D. 2008. Characterization of Fusarium graminearum Mes1 reveals roles in cell-surface organization and virulence. Fungal Genet. Biol. 45:933-946.

37. Rudd, J. C., Horsley, R. D., McKendry, A. L., and Elias, E. M. 2001. Host plant resistance genes for Fusarium head blight: Sources, mechanisms, and utility in conventional breeding systems. Crop Sci. 41:620-627.

38. Rychlik, M., and Asam, S. 2008. Stable isotope dilution assays in mycotoxin analysis. Anal. Bioanal. Chem. 390:617-628.

39. Sato, K., Hori, K., and Takeda, K. 2008. Detection of Fusarium head blight resistance QTLs using five populations of top-cross progeny derived from two-row $\times$ two-row crosses in barley. Mol. Breed. 22:517-526.

40. Schwarz, P. B., Schwarz, J. G., Zhou, A., Prom, L. K., and Steffenson, B. J. 2001. Effect of Fusarium graminearum and F. poae infection on barley and malt quality. Monatsschr. Brauwiss. 3/4:55-63.

41. Uhlig, S., Jestoi, M., and Parikka, P. 2007. Fusarium avenaceum-the North European situation. Int. J. Food Microbiol. 119:17-24.

42. Urrea, C. A., Horsley, R. D., Steffenson, B. J., and Schwarz, P. B. 2005. Agronomic characteristics, malt quality, and disease resistance of barley germplasm lines with partial Fusarium head blight resistance. Crop Sci. 45:1235-1240.

43. VDLUFA. 2006. Methodenbuch III-Die chemische Untersuchung von Futtermitteln, method 16.12.1, VDLUFA Verlag, Darmstadt, Germany.

44. Yli-Mattila, T., Paavanen-Huhtala, S., Jestoi, M., Parikka, P., Hietaniemi, V., Gagkaeva, T., Sarlin, T., Haikara, A., Laaksonen, S., and Rizzo, A. 2008. Real-time PCR detection and quantification of Fusarium poae, F. graminearum, $F$. sporotrichioides and $F$. langsethiae in cereal grain in Finland and Russia. Arch. Phytopathol. Plant Prot. 41:243-260.

45. Zhu, H., Gilchrist, L., Hayes, P., Kleinhofs, A., Kudrna, D., Liu, L., Prom, L., Steffenson, B., Toojinda, T., and Vivar, H. 1999. Does form follow function? Principle QTLs for Fusarium head blight (FHB) resistance are coincident with QTLs for inflorescence traits and plant height in a double-haploid population of barley. Theor. Appl. Genet. 99:1221-1232. 